\title{
Flywheel Energy Storage for Rural Residential Applications Supplied by Intermittent Wind Power
}

\author{
Ahmed T. Elssayed ${ }^{1}$, Tarek A. Youssef ${ }^{1}$, and Osama A. Mohammed ${ }^{1}$ \\ ${ }^{1}$ Energy Systems Research Laboratory, USA, mohammed@fiu.edu
}

\begin{abstract}
Driven by the environment concerns and high pollution rates, a global trend is initiated towards more deployment and utilization of renewable energy sources. This paper investigates the utilization of wind turbine system to supply residential loads in an isolated area. I.e. there's no connection to the grid. In order to assure that the entire system is clean and has no environmental impacts, a chemical free energy storage is attached to the wind turbine. A flywheel which is sometimes called "electromechanical battery" is used here as a clean energy storage. The simulation results reveal the superior performance of the system. It is successful to cover the loads and continue operation without any reliance on the grid connection. This configuration can help to promote more utilization of wind turbines. This because the proposed configuration compensates for one of the most disadvantageous properties of wind power which is the intermittency.
\end{abstract}

Keywords - Clean supply system, flywheel energy storage, residential applications, rural area, wind power.

Digital Object Identifier (DOI): http://dx.doi.org/10.18687/LACCEI2015.1.1.106

ISBN: 13 978-0-9822896-8-6

ISSN: $2414-6668$

13 ${ }^{\text {th }}$ LACCEI Annual International Conference: “Engineering Education Facing the Grand Challenges, What Are We Doing?” July 29-31, 2015, Santo Domingo, Dominican Republic DOI: http://dx.doi.org/10.18687/LACCEI2015.1.1.106 


\title{
Flywheel Energy Storage for Rural Residential Applications Supplied by Intermittent Wind Power
}

\author{
Ahmed T. Elssayed, Student Member IEEE, Tarek A. Youssef, Student Member IEEE, \\ and Osama A. Mohammed, Fellow IEEE \\ Energy Systems Research Laboratory, Department of Electrical and Computer Engineering \\ Miami, Florida, USA, mohammed@fiu.edu
}

\begin{abstract}
Driven by the environment concerns and high pollution rates, a global trend is initiated towards more deployment and utilization of renewable energy sources. This paper investigates the utilization of wind turbine system to supply residential loads in an isolated area. i.e. there's no connection to the grid. In order to assure that the entire system is clean and has no environmental impacts, a chemical free energy storage is attached to the wind turbine. A flywheel which is sometimes called "electromechanical battery" is used here as a clean energy storage. The simulation results reveal the superior performance of the system. It is successful to cover the loads and continue operation without any reliance on the grid connection. This configuration can help to promote more utilization of wind turbines. This because the proposed configuration compensates for one of the most disadvantageous properties of wind power which is the intermittency.
\end{abstract}

Keywords-Clean supply system, flywheel energy storage, residential applications, rural area, wind power.

\section{INTRODUCTION}

Recently flywheel Energy Storage System (FESS) has attracted new research attention in several applications such as improving power quality and uninterruptible power supplies (UPS). One of the applications that FESS can be of much interest is combined with wind power where the generated energy is very intermittent. The reason for this recent research interest is due to the latest developments of relevant technology, such as magnetic levitation, composite materials, low-loss machinery and power electronic switch, particularly in high-power insulated-gate bipolar transistors (IGBTs) and field-effect transistors (FETs) [1][3]. It was found that the flywheel is a very reliable solution for short term energy storage, it can provide high power for short periods with range of few seconds. Compared with other traditional energy storage systems such as batteries and capacitors, flywheel has its own advantages; high dynamics, long life time and good efficiency. Moreover, it has less fire hazards because it is completely chemical free. Finally, the state-of charge of the flywheel is always easy to be known by measuring its rotational velocity.

Moreover, the sizing of the FESS is very flexible because the rated power capability is not directly tied to energy storage capacity since energy transfer, to charge and discharge a flywheel, is provided by motor-generator. Therefore, energy storage capacity and power capability can be flexibly tailored to meet specific grid requirements [4].

Based on these factors, it has been made possible, attractive and feasible to construct flywheels strong enough to operate reliably at high speed to achieve higher efficiency and higher stored energy. For example, the University of Texas at Austin has subjected a composite flywheel spinning at about 48,000 $\mathrm{r} / \mathrm{min}$ to more than 90,000 charge-discharge cycles with no loss of functionality (which is very high if compared to batteries). Another example is the FESS installed in an AMD semiconductor fabrication facility in Dresden, Germany. The system can supply or absorb $5 \mathrm{MW}$ for 5 seconds - that is, it can store $25 \mathrm{MJ}$. In addition, FESS is very promising to be used on the International Space Station as NASA estimates that more than US $\$ 200$ million will be saved if flywheels replace the first generation of space station batteries [5], [6].

One of the points that should be taken into consideration is the selection of the motor/generator combined with the flywheel, high speed operation and high reliability requirements limit the available selections to brushless and permanent magnet (PM) machines. PM machines offer higher efficiency, smaller size for the same rating, lower rotor losses and lower winding inductances which make them more suitable for rapid energy transfer in flywheel applications [1],[7]-[9].

FESS operates in three operating conditions: charge, standby and discharge. In the charging mode, the power grid injects energy into the flywheel through a bi-directional converter. When the flywheel reaches to the maximum stored kinetic energy limit, the FESS moves into the standby mode in which the charging current is kept small to maintain it charged and spinning at the rated speed. If a power outage occurs, the FESS switches into the discharge mode, the Permanent Magnet Synchronous Machine (PMSM) acts as a generator to provide energy to loads through bi-directional power converter. When the power grid recovers from failure, the FESS re-enters the charge mode and ready to handle the next power quality event.

This paper presents the integration of a flywheel energy storage system (FESS) with a wind turbine to supply power for a residential. The system understudy is located in a total area where there's no connection to the grid. The main supply for electricity is a wind plant. However, it is well known that the

$13^{\text {th }}$ LACCEI Annual International Conference: “Engineering Education Facing the Grand Challenges, What Are We Doing?" July 29-31, 2015, Santo Domingo, Dominican Republic ISBN: 13 978-0-9822896-8-6 ISSN: 2414-6668

DOI: $\underline{\text { http://dx.doi.org/10.18687/LACCEI2015.1.1.106 }}$ 


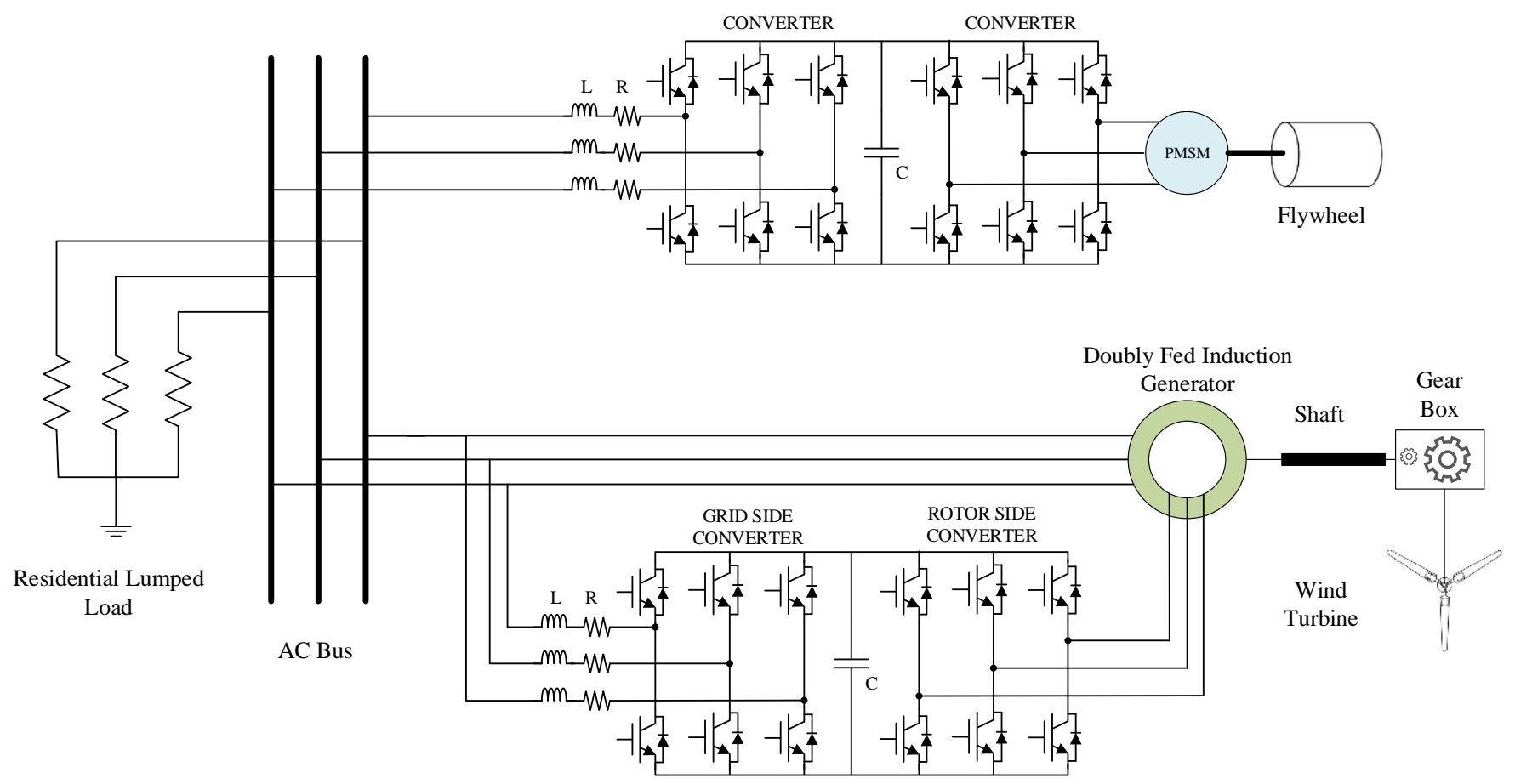

Fig. 1 System understudy.

intermittent nature of wind power prevents the sole reliance on it. Thus an energy storage should be combined to it. In this study the FESS is selected to be used to compensate for wind power intermittency. Real wind data and load patterns are selected to be used in this study.

The rest of this paper is organized as the following: section II presents a brief discussion about the doubly Fed Induction generator (DFIG) which will be used in this study. A detailed description of the system under study is presented in section III. The results of the simulation along with analysis and discussion are provided in section IV. The conclusion of this work is outlined in section V.

\section{DFIG BASED WIND TURBINE}

The Double Fed Induction Generator (DFIG) consists of wound rotor induction machine and two power electronic converters. The stator of the DFIG machine is coupled directly with the AC grid without any power electronics interface. The wound rotor is connected to the grid through bidirectional ACDC-AC converter. The AC-DC-AC converter consists of two back to back inverters with common DC bus. Active and reactive power supplied by the DFIG can be controlled and regulated through the power electronics converter. The power electronics converter controller consists of two sub controllers, rotor side controller and grid side controller [10]. The rotor side controller regulates the DFIG speed and the reactive power [11]. Different reactive power control strategies can be used to regulate the terminal voltage at the point of common coupling by injecting necessary reactive power or power factor improvement [12]. The grid side controller controls the total power supplied to the grid by controlling the power injected from the rotor to the grid when the generator slip is greater than zero or rotor absorbed power when the slip is less than zero [10]. The total supplied power by the DFIG is calculated as:

$$
\mathrm{P}_{\mathrm{DFIG}}=\mathrm{P}_{\text {rotor }}+\mathrm{P}_{\text {stator }}
$$

The DFIG shows advantages over the other types of variable speed generators used in wind power applications. Compared with full converter synchronous generators the DFIG uses smaller size power electronics converter which reduces the cost and size. The power electronics converter in DFIG process only 25-30\% [1] of total power produced by the wind turbine compared with $100 \%$ converter rating in full converter topology. DFIG has wide speed rang compared with direct coupled induction machine which operation is limited within the sub-synchronous speed. On contrast, the DFIG can work in sub-synchronous and super-synchronous speeds with slip rang $+/-0.3$.

Moreover, active and reactive power can be easily regulated through the power electronic converter. However, one of the main disadvantages of the DFIG is the performance of the system during gird disturbance. Since the stator is connected directly to the grid a voltage transient could produce high current on the stator winding. Usually the stator winding can withstand this current but it could cause damage to the rotor side converter. In order to protect the power electronics 
converter a protection scheme is employed. This scheme involves a crowbar circuit is used to protect the system from over current on rotor winding or over voltage in the DC link.

\section{SYSTEM DESCRIPTION}

The system understudy is shown in Fig. 1, as it can be seen a DFIG based wind turbine connected to an AC bus. In parallel a flywheel based energy storage systems is connected to smooth the output of the wind turbine. The flywheel construction is based on Permanent Magnet Synchronous Machine (PMSM) coupled to a steel mass. The energy is stored as kinetic energy in the rotating mass. The PMSM is operated in two modes; the motor mode during the charging and generator mode during the discharging. The rated speed of the machine is $1750 \mathrm{rpm}$ which is corresponding to 183.25 $\mathrm{rad} / \mathrm{sec}$. The equivalent moment of inertia of the rotating disc is $8 \mathrm{~kg} / \mathrm{m}^{2}$.

The two systems are connected in parallel to the AC bus. A lumped load is connected to the system to represent the load of residential building or community. It is worthy to mention here that the used data for the simulation is real data for the wind speed and load patterns. These data patterns are collected from area in Texas. The operation of the system is as the following: when the available power from the wind is more than the load, the flywheel controller is commanded to charge the flywheel. In this mode the machine is operated as a motor and the energy is transferred to be stored as a form of speed increase. The State of Charge of the flywheel is identified by its speed. The amount of energy stored in a flywheel is expressed as:

$$
E_{f w}=\frac{1}{2} \cdot \mathrm{J} \cdot \omega_{f w}^{2}
$$

Where $\mathbf{J}$ is the moment of inertia and $\omega$ is the rotational speed. Since the moment of inertia of the rotating mass is constant over the entire period of operation the speed accurately reflects the amount of the stored energy. Vice versa when the load exceeds the generated power from wind turbine the stored energy is transferred back to the AC bus. In this mode the machine is operated as a generator, the rotating mass with its stored energy acts as the prime mover. Fig. 2 illustrates this process. The charging area is indicated by the red region while the discharging area is indicated by the green region. The net difference between the generated power from the wind turbine minus the load is plotted using the solid blue line. The charging and discharging processes of the flywheel are controlled through two independent PI control loops.

\section{SIMULATION RESULTS}

In order to investigate the performance of the system in islanded operation, a model of the system is built using
MATLAB/Simulink. The wind and load patterns for a real system are used. However, the available data is hourly, running the simulation for hours is not feasible. Thus the system is down scaled for seconds. i.e. each second in the simulation represents one hour in the real time. Sine, the energy stored in the flywheel is function in time, it is very important to down scale the flywheel size as well. The energy is divided over 3600. In other words the size of the flywheel used in the simulation should be multiplied by 3600 to be implemented in a real system in the real time (in hours). For more validation of the system, the simulation running time was selected to be $72 \mathrm{sec}$.

The simulation results are depicted in Fig. 3. Fig. 3(a) shows the load power in kW. Fig. 3(b) shows the net output power from the wind turbine which is fluctuating over a wide range. The energy of the flywheel is shown in Fig. 3(c), it can be seen that the flywheel is dynamically supplying the load during the shortage periods of the wind. It should be highlighted here that a smart charging algorithm is adopted to prevent the flywheel from withdrawing high current during charging. It is known that during the charging of a machine, if the rated voltage is applied suddenly then a high current will be withdrawn from the supply which may cause voltage or frequency disturbances in the system. Here, the voltage reference for the machine is applied gradually to allow soft charging of the flywheel. The notation used in this figure that the injected power to the system is positive and the withdrawn from the system is negative. The smooth charging is clear when the power is negative (during charging process). The line to line voltage of the AC bus is shown in Fig. 3(d), negligible fluctuations within $\pm 1.5 \%$ are shown. This level of fluctuations is allowed by all the standards including

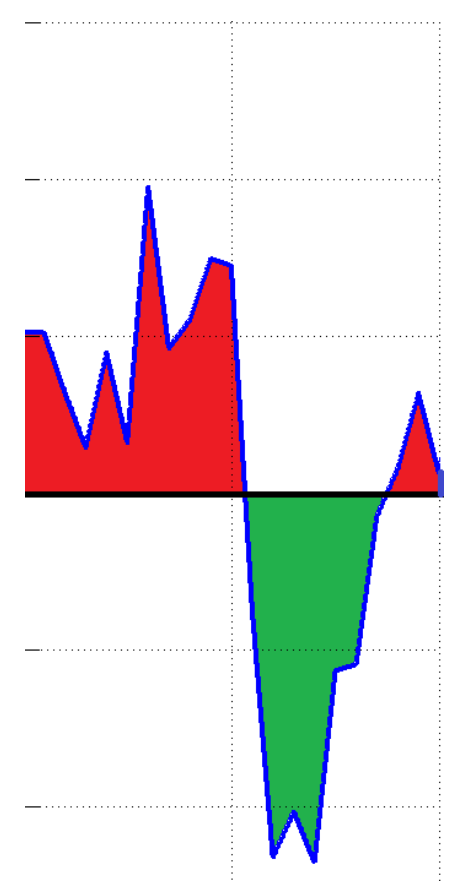

Fig. 2. Charging/discharging of FESS.

13 ${ }^{\text {th }}$ LACCEI Annual International Conference: "Engineering Education Facing the Grand Challenges, What Are We Doing?" July 29-31, 2015, Santo Domingo, Dominican Republic 


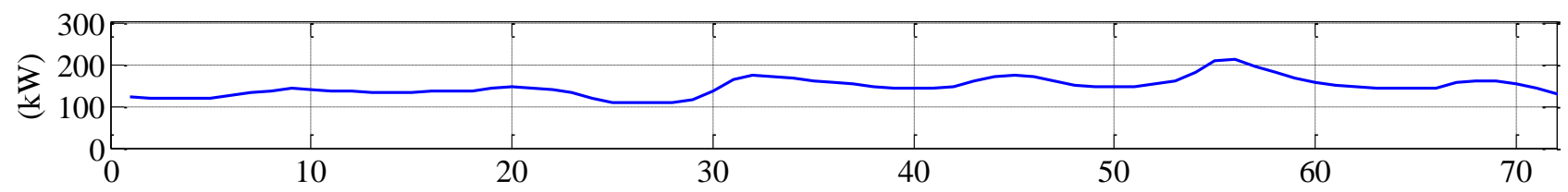

(a)

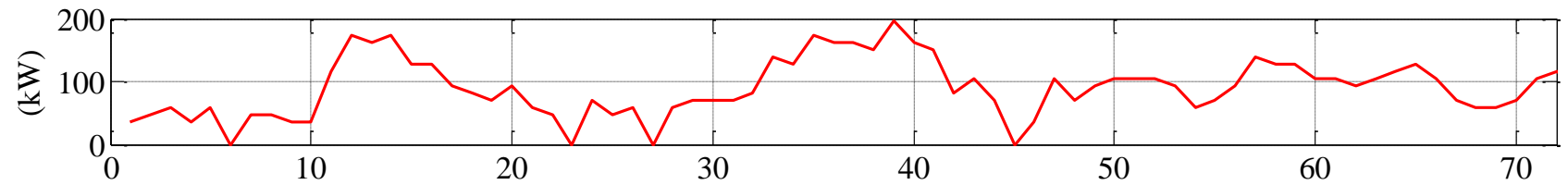

(b)

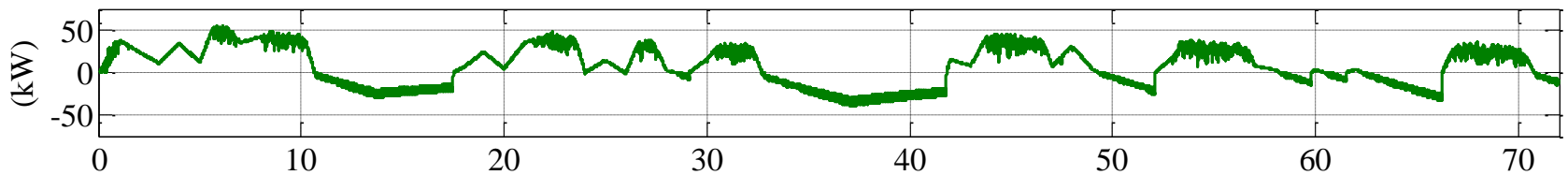

(c)

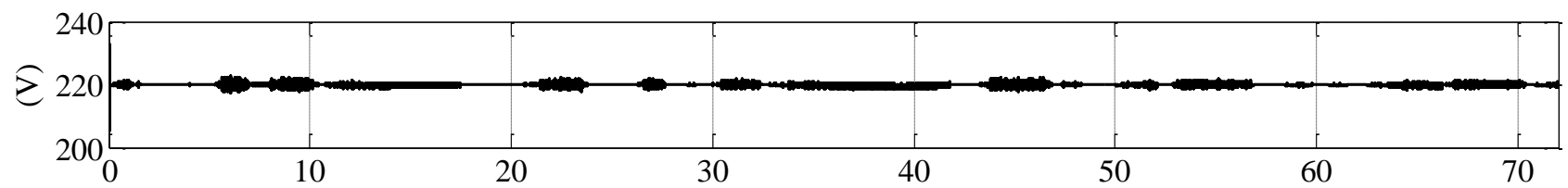

(d)

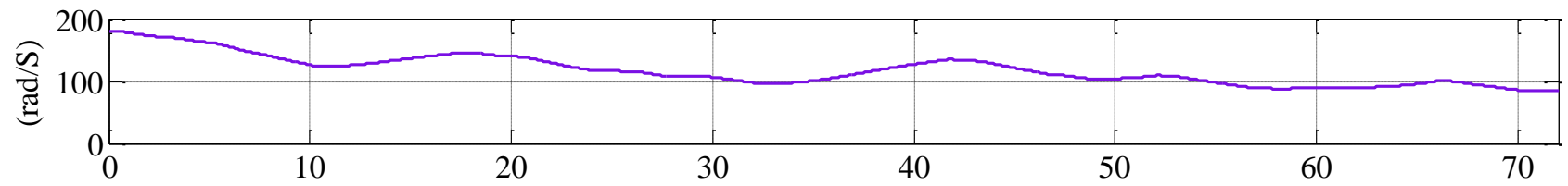

(e)

Time (Sec)

Fig. 3 Simulation results (a) Load power in $\mathrm{kW}$, (b) output power from the wind turbine in $\mathrm{kW}$, (c) output power from the FESS in $\mathrm{kW}$, (d) AC bus voltage in (V), (e) flywheel speed in $\mathrm{rad} / \mathrm{sec}$.

NEC [13]. The speed of the flywheel is shown in Fig. 3(e). As mentioned earlier the machine speed reflects the SoC of the flywheel. The soft charging of the flywheel is seen here through the gradual increase in the machine speed. It can be concluded that the system is capable of running independently from the from connection

\section{CONCLUSION}

A flywheel energy storage system (FESS) is utilized to compensate for the intermittency of the wind power. Wind turbine is used in conjunction with a FESS to cover the electricity demand of a rural residential area. A simulation model is built in MATLAB/Simulink to investigate the performance of the system and its capability to continue supplying the demand. The simulation results showed that the system is operating continuously without any grid connection. Voltage fluctuations were negligible and within the allowed limits which indicates stable operation. The entire system is clean and it doesn't involve any chemicals or fossils. The operation of flywheel to smooth the output power of wind power system can be promising idea for more deployment of such systems. Also, this system can be used in promoting electrification in rural areas.

\section{REFERENCES}

[1] H. A. Toliyat, S. Talebi, P. McMullen, Co Huynh and A. Filatov, "Advanced high-speed flywheel energy storage systems for pulsed power applications," IEEE Electric Ship Technologies Symposium, PP. 379386,2005

13 ${ }^{\text {th }}$ LACCEI Annual International Conference: "Engineering Education Facing the Grand Challenges, What Are We Doing?" July 29-31, 2015, Santo Domingo, Dominican Republic 
[2] J. McGroarty, J. Schmeller, R. Hockney and M. Polimeno, "Flywheel energy storage systems for electric start and an all-electric ship," IEEE Electric Ship Technologies Symposium, PP. 400-406, 2005.

[3] L. Zhou, and Z. ping Qi, "Modeling and control of a flywheel energy storage system for uninterruptable power supply," IEEE International Conference on Sustainable Power Generation and Supply (SUPERGEN '09), 2009.

[4] C. S. Hearn, M. C. Lewis, and R. E. Hebner, "Sizing advanced flywheel energy storage," Center for Electromechanics (CEM), the university of Texas at Austin, Aug. 2012. "Available Online: http://www.utexas.edu/ research/cem/images/GCEP\%20Program.pdf"

[5] R. Hebner, J. Beno and A. Walls, "Flywheel batteries come around again," IEEE Spectrum, vol. 39, no. 4, pp. 46-51, 2002.

[6] Available Online: http://www.grc.nasa.gov/WWW/RT/2004/RS/RS10Sjansen.html

[7] R. Okou, A. Sebitosi, M. A. Khan, P. Barendsa, and P. Pillay "Design and analysis of an electromechanical battery for rural electrification in sub-Saharan Africa," IEEE Transactions on Energy Conversion, vol. 26, no. 4, pp. 1198-1209, Dec. 2011.

[8] A. S. Nagorny, N. V. Dravid, R. H. Jansen, and B. H. Kenny, "Design aspects of a high speed permanent magnet synchronous motor/generator for flywheel applications," in Proc. IEEE International Electric Machines and Drives Conference (IEMDC), 2005, pp. 635-641.

[9] T. D. Nguyen, K. J. Tseng, S. Zhang, and H. T. Nguyen, "A novel axial flux permanent magnet machine for flywheel energy storage system: Design and analysis," IEEE Transactions on Industrial Electronics, vol. 58, no. 9, pp. 3784-3794, Sep. 2011.

[10] H.T. Jadhav, Ranjit Roy, A comprehensive review on the grid integration of doubly fed induction generator, International Journal of Electrical Power \& Energy Systems, Volume 49, July 2013, Pages 8-18.

[11] Salles, M.B.C.; Filho, A.J.S.; Grilo, A.P., "A study on the rotor side control of DFIG-based wind turbine during voltage sags without crowbar system," Renewable Energy Research and Applications (ICRERA), 2012 International Conference on , vol., no., pp.1,6, 11-14 Nov. 2012

[12] Wang Weiguang; Qiu Tian, "A review of direct power control technologies of DFIG with constant switching frequency," Control and Decision Conference (CCDC), 2011 Chinese, vol., no., pp.2819,2822, 23-25 May 2011

[13] M. W. Earley, J. S. Sargent, C. D. Coache, and R. J. Roux “ National electrical code handbook," Twelfth edition, NFPA, 2011.

$1^{\text {th }}$ LACCEI Annual International Conference: "Engineering Education Facing the Grand Challenges, What Are We Doing?" July 29-31, 2015, Santo Domingo, Dominican Republic 